\title{
Synthetic versus long-term natural records of tropical cyclone storm surges: problems and issues
}

\author{
Jonathan Nott ${ }^{*}$ (1)
}

\begin{abstract}
The majority of risk assessments of tropical cyclone storm surge and inundations are based on the generation of synthetic times series from short historical records. The accuracy of these synthetic time series in terms of the frequency of the most extreme magnitude events is difficult to test using this methodology alone. Comparisons with other approaches such as deterministically derived synthetic time-series and/or long-term natural records of these events are required. Major discrepancies often arise when such comparisons are made especially when it becomes evident that the frequency of extreme events is under-represented in the short historical records upon which the synthetic time series are based. The solution to the problem though is not as simple as replacing one type of time series with the other. As the number and the types of long-term natural records increase, it is becoming apparent that non-stationarity is an inherent feature of the natural variability of these events. This non-stationarity can be manifested as distinct periods of time, in the past, of varying event-frequency probabilities, which, at least in some cases, have climatic causes. In these cases, it may not be appropriate to use entire long-term record sets for risk assessments because certain periods of time or sections of these records may have event frequencies resulting from climate states substantially different to that expected in the future. Identifying the most appropriate past climate states and associated event behaviour may serve as better analogues for assessing future risk.
\end{abstract}

Keywords: Tropical cyclones, Synthetic times series, Palaeocyclone records

\section{Introduction}

The consequences of many natural hazards are expected to worsen in the near future due to anthropogenically induced climate change and the increasing vulnerability of communities when they are located in the path of hazards. Detecting changes in the behaviour (intensity and frequency) of hazard events in order to ascertain any possible attribution to climate change and also assessing the future physical risk to communities from these hazards have been largely based on the generation of synthetic time series from short historical records (McInnes et al. 2003; Hardy et al. 2004; Brettschneider 2008; Hall and Jewson 2008; Hallegatte et al. 2011; Haigh et al. 2014). A major assumption in this process is the historical

\footnotetext{
*Correspondence: Jonathan.Nott@jcu.edu.au

College of Science, Technology and Engineering, James Cook University, Cairns, QLD, Australia
}

record is a reasonable reflection of the longer-term natural variability of the hazard event in question (Liu and Fearn 2000; Nott and Hayne 2001; Donnelly and Woodruff 2007). Testing this assumption is difficult using this methodology alone because it requires waiting for sufficient time to elapse (centuries to millennia) in order to instrumentally record the longer-term natural variability (Haig et al. 2014; Nott 2006). Nature, however, provides its own long-term records of events. And while these natural records are ideally suited for testing assumptions made from short historical records, the outcomes of these comparisons are rarely incorporated into the synthetic time-series methodology (Nott 2006, 2011). The historical records upon which many synthetic time series are based are often too short to capture the most extreme events, and as such, these records regularly underestimate the frequency of the highest magnitude events. As a

\section{包 Springer}

(c) 2016 Nott. This article is distributed under the terms of the Creative Commons Attribution 4.0 International License (http:// creativecommons.org/licenses/by/4.0/), which permits unrestricted use, distribution, and reproduction in any medium, provided you give appropriate credit to the original author(s) and the source, provide a link to the Creative Commons license, and indicate if changes were made. 
consequence, communities are unwittingly located in the path of hazards, which may not have occurred if longerterm natural records had been used in conjunction with the existing planning policies (Nott 2011). There are many types of natural hazards to which this situation applies such as marine (storm and tsunami) and riverine flooding, and earthquakes and volcanoes to name just a few (Nott 2006). In this paper, however, the focus will be on storm surges and associated marine inundations generated by tropical cyclones. The examples presented highlight the gulf between the synthetic and natural record approaches in attempting to understand the longterm variability of these events. Solutions are suggested that might help merge these records together in order to generate more robust physical risk scenarios for communities potentially at risk from these events and from which detection of human-induced changes to the frequency and magnitude of events can be discerned.

\section{Review}

There have been two main approaches to developing long-term tropical cyclone (TC) climatologies over the last two decades. One uses the recent historical record of TCs, generally since 1970 when radar and satellite data became available, to generate statistical models of TC behaviours that form the basis of synthetically derived time series designed to simulate thousands of years of TC activity (McInnes et al. 2003; Hardy et al. 2004; Brettschneider 2008; Hall and Jewson 2008; Hallegatte et al. 2011; Haigh et al. 2014). The other has been to examine geological and geochemical records of actual TC events that have occurred over the past several centuries to millennia (Liu and Fearn 2000; Nott and Hayne 2001; Donnelly and Woodruff 2007; Haig et al. 2014). Both of these approaches produce substantially different conclusions regarding the long-term climatology of TCs.

The geological or palaeo-TC approach relies upon the fact that extreme events such as TCs, river floods, droughts, tsunami, volcanic eruptions and earthquakes to name just a few leave their signatures in the landscape or other natural archives such as tree rings, corals, stalagmites, ice caps and sediments on the ocean floor and lakes (Nott 2006). In the case of sedimentary deposits, these signatures can be preserved because they have been emplaced in locations within the landscape that subsequent lesser magnitude events are unable to reach and hence erode. Other archives such as stalagmite layers and sedimentary layers within lagoons or on the ocean floor maybe capped or overlain by subsequent layers, or in some cases, induration of the deposit can occur making it more resistant to erosion. The key point about these event signatures is they are preserved. Some of these signatures are proxies, but others are not because they directly record the magnitude and/or frequency of the event. Sedimentary deposits left by marine inundations are prime examples of direct records because they register the height, often minimum, of that inundation. These records can be regarded as reliable and be used as a measure of the minimum magnitude of the event, provided little or nothing has changed to the physical landscape in which these records are left or within which they were generated.

In the case of TCs, there are 15 different types of evidence used for reconstructing long-term records of TCs (Nott 2011). The main types used to date are sedimentary deposits, such as overwash sediments and beach ridges, and isotope records found within limestone stalagmites (Haig et al. 2014; Frappier et al. 2007; Nott et al. 2007). A common characteristic of many long-term records is that they show alternating periods of lesser and heightened TC activity (Nott and Forsyth 2012). These periods vary in length depending upon the chronological resolution and nature of the record. The coarser scale, but generally longer, sedimentary records show these alternating periods can be several centuries to a millennium in length (Donnelly et al. 2015; Woodruff et al. 2015; Nott 2015). The shorter, but much higher resolution, isotope records demonstrate that alternating periods of activity also occur at decadal to centennial scales (Haig et al. 2014; Frappier et al. 2007; Nott et al. 2007). The fact these alternating episodes occur highlights that non-stationarity is an inherent feature of the natural variability of TCs. This non-stationarity, however, is not accommodated, or even considered, in the generation of long synthetic time series of TCs.

Another key aspect of the long-term natural TC records is they often reveal a higher frequency of highmagnitude events than what occurs in the synthetically generated time series. While all of the natural records are able to provide a frequency of events, the ability to obtain magnitudes varies. Two main approaches have been developed to determine the magnitude of past TC-generated marine inundations. The first measures the actual or minimum height of past inundations from beachridge deposits, while the other examines the texture and distribution of sand-sized particles within back barrier lagoon deposits. One of these, the beach-ridge approach is discussed here. Details of the methods and approaches using the particle size distributions within sedimentary deposits emplaced in back barrier lagoons throughout the USA, Caribbean and Japan can be found in the literature (Donnelly et al. 2015; Woodruff et al. 2008, 2015; Lin et al. 2014).

\section{Natural long-term records-beach ridges}

The beach ridges in Northeast Queensland, Australia have been shown to accumulate through storm tide and 


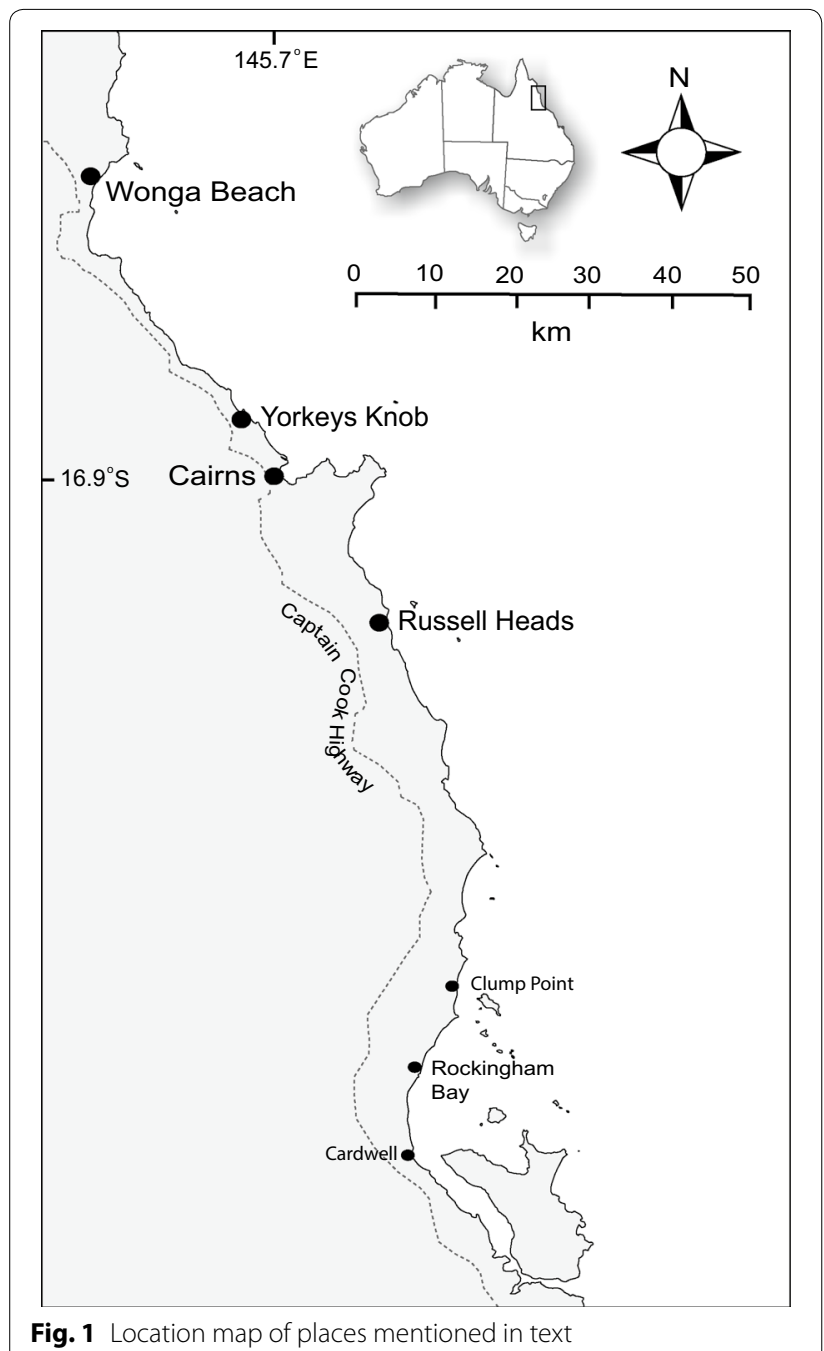

wave action combined. The same is true for the ridges in the Gulf of Carpentaria and in Shark Bay, Western Australia (Nott and Forsyth 2012). Not all beach ridges elsewhere around Australia, particularly in southern, temperate Australia and globally, accumulate in the same fashion. Some can form through aeolian action although Hesp (2006) would now define these as relict foredunes, but there has been some confusion previously in the literature about terminology. Wind plays a minimal, if any, role in the formation of the beach ridges identified thus far as palaeo-TC deposits. In short, numerous postTC event surveys reveal an absence of aeolian deposits resulting from the event (Nott and Forsyth 2012). In most situations examined so far, the only substantial deposits have been generated by marine inundations. Coral shingle ridges can be deposited in their entirety during a single TC event (Nott 2003; Maragos et al. 1973), but the coarse-grained sand beach ridges appear to accumulate progressively over time.
TC-generated marine inundations that can overtop a sand beach-ridge deposit a unit of sediment causing the ridge to grow progressively in height. A range of different magnitude inundations can be responsible for depositing a ridge until the ridge approaches a height that is attainable by wave run-ups generated by only very intense TCs. Hence, the final units of sediment deposited on the ridge will be due the most extreme inundations. The initial units of sediment constituting a ridge (those lowest in the ridge stratigraphy) could have been deposited by a range of inundations starting from non-cyclonically induced inundations, such as very high tides and strong trade wind-generated wave conditions, to the most intense TC-generated inundations. Progressively higher inundations are required to deposit sand onto the ridge crest as that ridge grows in height. A point will be reached where the vast majority of inundations can no longer reach the ridge crest and the ridge will cease to increase in height. The time when this terminal point occurs may also be influenced by the rate of growth of the next seaward ridge. This ridge is likely to have already been initiated before the ridge to its landward side has reached its maximum height. In the case of the ridge plains along the wet tropical coast of northeast Queensland, the final inundations responsible for depositing the uppermost units of sediment on the beach ridges were generated by extreme intensity TCs (Nott et al. 2009; Forsyth et al. 2010). Hence, the heights of these ridges and the methods developed by Nott (2003) for calculating the intensity of the TCs responsible allow a 5000- to 6000-year record of intense TCs to be determined. Past variations in sealevel and various tide states are incorporated into these time series, and in so doing, estimates of both the intensity and frequency of tropical cyclones over the millennia can be estimated.

Nott and Jagger (2013) applied generalised extreme value and Bayesian analysis techniques to a sand beachridge plain at Rockingham Bay (Tully Heads), north Queensland (Fig. 1) to derive a return interval plot of inundations. The inundation at this location (Tully Heads) during TC Yasi 2011 was surveyed (by J. Nott) at 5.1-m AHD. This level included storm tide plus wave set-up but not wave run-up as the inundation completely overflowed the land surface here. The inundation by TC Yasi at Cardwell, approximately $20 \mathrm{~km}$ south of here, was measured by tide gauge at 4.5-m AHD (surge equal to $5.5 \mathrm{~m}$ ). The total inundation at Cardwell, including wave set-up and wave run-up was 6.1-m AHD (surveyed by J. Nott). The storm tide was about $70 \%$ of the total inundation here, and the same relationship was true for Clump Point, approximately $30 \mathrm{~km}$ north of Tully Heads, where the tide gauge storm tide was 2.6-m AHD, and the total inundation reached 3.54-m AHD (as surveyed by 
J. Nott). Using the relationship between total inundation and storm tide measured at Cardwell and Clump Point, the storm tide at Tully Heads would have been greater than 3.5-m AHD (i.e. storm tide $=0.7 \times$ total inundation including wave run-up).

Nott and Jagger's (2013) analysis of the return intervals based on the palaeorecord (i.e. beach ridges) at Tully Heads differed considerably from the return interval plot for the same site generated by Hardy et al. (2004) using the synthetic time-series approach. Nott and Jagger (2013) found that the 5-m AHD total inundation (3.5-m storm tide) here during TC Yasi 2011 was equivalent to a 1 in 1000-year event ( $0.1 \%$ AEP) whereas Hardy et al. (2004) plot suggests this inundation was closer to a 1 in 10,000-year event. Hardy et al. (2004) storm estimate for the 1 in 1000-year event was $3.4 \mathrm{~m}$ which lies well outside of the uncertainty margin of $0.5 \mathrm{~m}(5 \pm 0.5 \mathrm{~m})$ for Nott and Jagger (2013) estimate of the same return interval event. Haigh et al. (2014) also generated an exceedance probability plot for this site, and theirs, like that of Hardy et al. (2004), suggests that this magnitude inundation equates to an approximately 1 in 10,000-year event.

The discrepancy between the return interval or exceedance probability plots generated by Nott and Jagger (2013) and Hardy et al. (2004) and Haigh et al. (2014) most likely occurs because Nott and Jagger (2013) used a record of TCs that actually occurred over the past 5000 years whereas the others use a synthetically generated climatology based on the short historical record of TCs. This historical period has been shown to underrepresent the frequency of high-magnitude events. Callaghan and Power (2011) analysis of historical TCs (back to $\mathrm{AD}$ 1870) in Queensland show that there has been a $62 \%$ decrease in the frequency of intense landfalling TCs in Queensland towards the present day. Haig et al's (2014) recent analysis of high-resolution isotope records of TCs showed that total seasonal TC activity in northeast Queensland is presently at its lowest level for approximately 600 years and for 1500 years in Western Australia. These same records also showed the most dramatic decline in seasonal TC activity in both Western Australia and Queensland has occurred since approximately AD 1960. Hence, the period from AD 1970 to the present is the most under-represented period of TC activity for many centuries in Queensland and over a millennia in Western Australia. Any attempts to generate a long-term climatology based on this period (since AD 1970) therefore are very likely to underestimate the frequency of events and especially the most extreme events. The same would be true using the entire historical record of TCs in Australia (i.e. back to the late 1800s) as Haig et al. (2014) show that the decline in TC activity has been occurring since the mid-to-late 1800s. This result fits with
Callaghan and Power's (2011) conclusions as it does also with the sand beach-ridge and coral shingle-ridge records (Nott and Hayne 2001; Nott 2003; Nott et al. 2009).

Nott (2015) used the statistical approach of Nott and Jagger (2013) and combined it with LiDAR-generated cross-sectional profiles of beach-ridge plains to develop a desktop, rapid means of assessing the return frequency of inundations for a variety of locations along the northeast Queensland coast. The results further supported the claim that return frequency analyses generated by the probabilistically generated synthetic time series substantially underestimate the frequency of the largest events as these events are under-represented in the shorter historical records. For example, the beach-ridge-derived 1000-year return interval storm tide at Wonga Beach, $60 \mathrm{~km}$ north of Cairns, is approximately 30-35\% higher than the synthetic estimates. The same is true at Yorkeys Knob and Russell Heads, $10 \mathrm{~km}$ north and $30 \mathrm{~km}$ south of Cairns, respectively (Tables 1 and 2) (Nott 2015). In the case of the 100-year return periods, the beach-ridgederived storm-tide levels are between 50 and $30 \%$ higher than the synthetic estimates. The interesting comparison is between the 100- and the 1000-year return periods for storm tides (Tables 1 and 2). The beach-ridge records suggest that the synthetically derived data underestimate the return periods by an order of magnitude for a given inundation level. Furthermore, the beach-ridge data suggest that the 100-year return period storm-tide levels are actually higher than the synthetic estimates for the 1000-year levels for the same site. For example, at Wonga Beach, the beach-ridge-derived 100-year return period storm-tide level is 2.73-m AHD (Nott 2015), whereas the 1000 -year return period level as determined by the synthetic approach is only 2.2-m AHD (Haigh et al. 2014) and 2.4-m AHD (Hardy et al. 2004). At Yorkeys Knob, the beach-ridge-derived 100-year storm tide is 3.15-m AHD, and the synthetic 1000-year level is 2.1-m AHD (Haigh et al. 2014) and 2.3-m AHD (Hardy et al. 2004). This same marked difference occurs at Russell Heads (Tables 1 and 2).

\section{Overwash deposits}

The deposition of sand layers, up to $0.5 \mathrm{~m}$ thick, in back barrier lagoons and swamps where fine-grained sediments are generally deposited, has been interpreted as evidence of storm washover events. Sediments within back barrier lagoons are normally muddy, organic, or fine grained. Interbedded sand layers within these finegrained sediments can be due to storm surge and waves overtopping a sand dune barrier, and transporting sand into an environment where it is not normally deposited. By geologically dating the sand layers, the longterm history of cyclones in a region can be ascertained. 
Table 1 Comparisons of 1000-year return period inundation heights between natural long-term records Nott (2015) and synthetic records of Haigh et al. (2014) and Hardy et al. (2004)

\begin{tabular}{llllll}
\hline Location & $\begin{array}{l}\text { Nott (2015) } \\
\text { (total inundation) }\end{array}$ & $\begin{array}{l}\text { Nott (2015) } \\
\text { (storm tide) }\end{array}$ & $\begin{array}{l}\text { Haigh et al. } \\
\text { (2014) }\end{array}$ & $\begin{array}{l}\text { Difference } \\
\text { to Nott (2015) }\end{array}$ & $\begin{array}{l}\text { Hardy et al. } \\
\text { (2004) }\end{array}$ \\
\hline Wonga beach & 4.5 & 3.15 & 2.2 & 0.95 & 2.4 \\
to Nott (2015)
\end{tabular}

Synthetic time-series studies report storm-tide (surge plus tide) inundation levels not total inundation (storm tide plus wave set-up, wave action and wave run-up). Difference columns refer to storm-tide inundation levels, and storm tide for this study is taken as $70 \%$ of total inundation. All heights refer to AHD

Table 2 Comparisons of 100-year return period inundation heights between natural long-term records Nott (2015) and synthetic records of Haigh et al. (2014) and Hardy et al. (2004)

\begin{tabular}{llllll}
\hline Location & $\begin{array}{l}\text { Nott (2015) } \\
\text { (total inundation) }\end{array}$ & $\begin{array}{l}\text { Nott (2015] } \\
\text { (storm tide) }\end{array}$ & $\begin{array}{l}\text { Haigh et al. } \\
\text { (2014) }\end{array}$ & $\begin{array}{l}\text { Difference } \\
\text { to Nott (2015) }\end{array}$ \\
\hline Wonga beach & 3.9 & 2.73 & 1.8 & $\begin{array}{l}\text { Hardy et al. } \\
\text { (2004) }\end{array}$ \\
to Nott (2015)
\end{tabular}

Synthetic time-series studies report storm-tide (surge plus tide) inundation levels, but not total inundation (storm tide plus wave set-up, wave action and wave run-up). Difference columns refer to storm-tide inundation levels, and storm tide for this study is taken as $70 \%$ of total inundation. All heights refer to AHD

It is important to demonstrate that these sand layers are indeed from storm surges during TCs and not from other sources such as river flow or tsunami. The marine origin of the sand layers can be ascertained through identification of marine environment micro- and macrofossils such as foraminifera and diatoms within them.

Sand-layer stratigraphies from washover events due to TCs have been studied predominantly along the shores of the Gulf of Mexico and the southeastern and eastern United States. Liu and Fearn (2000) examined sand layers in lakes along the Florida and Alabama coasts, and Donnelly et al. (2015) studied similar deposits in New England and New Jersey along the USA Atlantic coast. These deposits have also been examined in Puerto Rico and the Caribbean along with Japan (Woodruff et al. 2015; Woodruff et al. 2008). All these studies assume that the height and general nature of the barrier have remained unchanged over the length of the washover record. Such assumptions seem reasonable when separate sites some distance apart show the same chronology of events, or at least clusters of events, suggesting that some kind of regional factor influenced the behaviour of TCs at different times during the past.

\section{Deterministically derived time series}

Recently both overwash records from the USA and beach-ridge records from Australia have been compared with deterministically generated time series Lin et al. (2014) and Lin and Emannuel (2015). Deterministically derived time series are generated using a model that has little reliance on previous events or historical records but rather generates a range of scenarios based on various physical states of the ocean and atmosphere. This approach differs to the probabilistically derived time series as the latter is based on the generation of a distribution of historical events. This latter approach can be limited if the historical record contains few extreme events and hence underestimates the frequency of the most extreme events. Lin et al. (2014) compared their deterministic model approach to both historical records and palaeostorm surge/inundation deposits at Apalachee Bay, northwest Florida. The comparison between the deterministically derived synthetic dataset (equivalent to 5175 years) and the historical dataset (=161 years) showed that the surge level for the longer synthetic dataset was much higher at various return periods than the historical dataset. This is to a certain extent a function of the much longer length of record for the synthetic versus historical datasets and that the latter has a relatively low frequency of intense storms. However, the critical issue is in the application or use of the historical dataset as the basis for estimating risk. Any extrapolation from this record is bound to underestimate the return period of the larger-magnitude events. The results of Lin et al. (2014), for example, showed that there is a difference, using their synthetic record versus the historical record, of greater 
than $5 \mathrm{~m}$ in surge height for the 1000-year event and about $3 \mathrm{~m}$ for the 100-year event at one site (St Marks). Furthermore good agreement was found between the long-term (4000 year) overwash sedimentary records of TC inundations from these sites and those of Lin et al. (2014) deterministically derived synthetic record. Like the synthetic record, the palaeorecord contained a much higher frequency of extreme events than the historical record. The mean return period of storm surges greater than $5 \mathrm{~m}$ is about 40 years using the deterministic synthetic record and palaeorecords, whereas it is about 400 years based on the historical record.

Comparisons between Lin and Emmanuel (2015) deterministically derived time series for Cairns, northeast Australia and the beach-ridge palaeorecord here showed similar results to those found with the overwash records in Florida. Again, the deterministically derived time series was much closer to the beach-ridge-derived time series than it was with the time series derived from the historical record alone. Lin and Emannuel (2015) estimate of the 1000-year storm surge in Cairns is $3.5 \mathrm{~m}$, whereas those from the historical records are approximately 2.3 and $2.2 \mathrm{~m}$. The beach-ridge record from this region suggests a 1000-year event at approximately $3.2 \mathrm{~m}$ (Nott 2015).

\section{Natural variability of tropical cyclones and causes}

Both the longer-term sedimentary overwash records from the United States and the beach-ridge records from Australia suggest that the historical records of TCs (approximately past century) in many cases are anomalously quiet. There appears to have been distinct periods of time over the past several millennia when TC activity has been high and others when it is much lower. There have been two periods of heightened activity in the Western north Atlantic between 150 and 1150 C.E. and 1400 and 1675 C.E (Donnelly et al. 2015). The first of these resulted in heightened TC activity across the broader Western north Atlantic between 150 and 1150 C.E. The east coast of the USA then appears to have experienced a period of quiescence between 1150 and 1400 C.E., whereas the Caribbean and Gulf of Mexico remained active until 1400 C.E. After this, the USA east coast became active again between 1400 and 1650 C.E. Donnelly et al. (2015) suggest that the earlier of these active periods (150-1150 C.E.) was a result of a more northerly position of the intertropical convergence zone (ITCZ) and higher sea surface temperatures (SST) throughout the region. Relatively cool SSTs occurred off the USA east coast between 1150 and 1400 C.E., and this resulted in reduced TC activity in this region; however, TC activity remained high in the Caribbean and Gulf of Mexico. A reorganization of atmospheric and oceanic conditions around 1400 C.E. resulted in cooler SSTs in the Main Development Region for hurricane formation in the western North Atlantic and the southward movement of the ITCZ resulting in lower TC activity in the Caribbean and Gulf of Mexico. At the same time ( 1400 C.E.), SSTs appear to have experienced a rapid rise of approximately $2{ }^{\circ} \mathrm{C}$ along the N.E. USA coast, possibly due to the increased influence from the Gulf Stream, and the palaeostorm inundation reconstructions from this region suggest an increase in TC activity at this time. A similar situation occurs in the N.E. Australian region (Coral Sea) where there was heightened TC activity between approximately 1400 and 1800 C.E. (Haig et al. 2014; Nott et al. 2007) associated with warmer SSTs in the Coral Sea (Hendy et al. 2002) compared to the period before and after, excluding the recent rise in SSTs in the later twentieth century likely associated with anthropogenically induced global warming.

The long-term natural records of TCs from both the USA and Australia highlight the marked variability in TC activity over time and the likely influence that various climate states have in controlling this variability. These records suggest that non-stationarity is an inherent feature of the natural variability of TCs as it is with many other extreme events such as droughts and floods (Nott 2006). A majority of synthetic time series of TCs to date, particularly those based on historical records, have not accommodated this non-stationarity. Simply creating longer synthetic times series, by undertaking further model runs, is unlikely to capture this variability as the distributions describing the various attributes of the TC climatology are still based on historical records that may under-represent the more extreme events.

The climatically controlled variability apparent in the longer-term records suggests that the true natural variability of TCs is composed of discrete periods of time with different frequency probabilities. Hence, the period between 1400 and 1650 C.E. along the N.E. USA coast must have had a higher probability of occurrence of the more extreme events than the centuries before and after. Likewise, the period from approximately 1400 to 1800 C.E. along the N.E. Australian coast also had a higher probability of occurrence of category 4 and 5 TCs making landfall than the present day. Assessing risk therefore needs to consider these periods of variable probabilities, which could otherwise be termed probability regimes (PRs).

Understanding the future behaviour of TCs requires knowledge of the current PRs and the climatic or potentially other causes responsible. It is also important to understand the nature of and if possible causes of other PRs within a long-term record. Some of these PRs may be associated with different climatic conditions to that 
expected in the future. Hence, it may not be appropriate to use an entire long-term natural record of events to assess risk; the current day PR, or other PR from the long-term record, may be an adequate period from which to base the probability of future events. Indeed, some PRs within a long-term record may be very different in character to that expected in the future so their use in a risk assessment may substantially skew any such forecasts. However, the longer-term natural record is critical for understanding the nature of the current and all PRs and the conditions responsible. Without the longer-term record, it would be difficult to know how long the current PR has been occurring, and therefore the maximum length record appropriate for risk assessments. Furthermore, without understanding the sequence and possible causes of previous PRs, it will likely be difficult to determine the mechanisms causing the current PR and when it might be likely to end. This will, to a certain extent, dictate how far into the future a current risk assessment might be relevant.

The detection of changes in behaviour of TCs, such as their frequency or total seasonal activity (Haig et al. 2014; Webster et al. 2005); intensity over time (Webster et al. 2005; Emanuel 2005; Elsner et al. 2008) and as a function of variability in Potential Maximum Intensity (Holland and Bruyere 2013); latitudinal extent (Kossin et al. 2014); and then ascribing causes for those changes, requires an understanding of the longer-term variability of these events. The question being asked here is what is the most appropriate length of record given the recognition now that different periods of time have experienced variable frequencies/probabilities due to different climate states. Is it in other words relevant to include the period between 1400 and 1650 C.E. in the N.E. USA or between 1400 and 1800 C.E. in N.E. Australia as part of the record of natural variability as a basis for forecasting the future behaviour of TCs? If the same oceanic current (i.e. Gulf Stream) conditions were expected to occur in the future as occurred between 1400 and 1650 C.E. in the N.E. USA region, then maybe it is appropriate to incorporate this time period. However, if not, then maybe another period of time i.e. the historical period or possibly an earlier one might have experienced boundary conditions more analogous to that expected over the next century. Anthropogenic climate change is expected to result in a doubling of El Nino events (Cai et al. 2014), which in the Australian region typically results in fewer TCs making landfall in Eastern Australia with a higher proportion of TCs developing east of approximately $170^{\circ} \mathrm{E}$ (Diamond et al. 2013). The period from 1400 to 1800 C.E. was thought to have experienced more La Nina-like conditions across the S.W. Pacific due to the movement southward of the ITCZ during a cooler phase of Earth's climate (Sachs et al. 2009; Yan et al. 2011). The ITCZ, however, is expected to move further north under a future climate (Broecker and Putnam 2013), and hence the period from 1400 to 1800 C.E. may not be a relevant episode to consider when assessing the future behaviour of TCs in Eastern Australia. Finding appropriate PRs that reflect future conditions requires a sharper focus on long-term natural records and further highlights their importance in reducing risk.

\section{Conclusions}

The generation and use of synthetic time series, particularly those based on short historical records, have formed the basis for the majority of risk assessments of tropical cyclone storm surge. Considerable uncertainties exist with this approach particularly when the short historical records do not accurately reflect the true variability of the most extreme events. Increasing the number of model runs as a means of increasing the variability within the synthetic time series does not overcome this problem because the various meteorological and oceanographic parameters associated with the underlying probability distributions do not change. Testing the accuracy of this approach can be done in two ways. The first is to use deterministically generated synthetic times series, and the other is to use long-term natural records of events. Both of these approaches have highlighted problems with the probabilistic synthetic time-series approach when the frequency of the most extreme magnitude events is under-represented in the historical record. Using longterm natural event records can also highlight changes in event-probability regimes over time. Such a regime change appears to be evident in both the N.E. USA and N.E. Australian regions between 1400 and 1650 C.E. and 1400 and 1800 C.E., respectively, when the frequencies of intense TCs were higher compared to the period since. The recognition of periods of variable event probabilities raises questions about the appropriate length of natural record to use for assessments of future risk. Previous periods of heightened event activity may have occurred during climatic conditions unlike that expected in the near future. Choosing periods in the past when climatic conditions were more analogous to that expected in the future may be more appropriate for making comparisons with or basing assessments of future risk.

\section{Competing interests}

The author declares that he has no competing interests.

Received: 17 September 2015 Accepted: 14 February 2016 Published online: 03 March 2016 


\section{References}

Brettschneider B (2008) Climatological hurricane landfall probability for the United States. J Appl Meteorol Climatol 47:704-717

Broecker WS, Putnam AE (2013) Hydrologic impacts of past shifts of earth's thermal equator offer insight into those to be produced by fossil fuel $\mathrm{CO}_{2}$. Proc Natl Acad Sci 110(42):16710-16715

Cai W et al (2014) Increasing frequency of extreme El Niño events due to greenhouse warming. Nat Clim Change 4:111-116

Callaghan J, Power S (2011) Variability and decline in the number of severe tropical cyclones making land-fall over eastern Australia since the late nineteenth century. Clim Dyn 37:647-662

Diamond H, Lorrey A, Renwick J (2013) A Southwest pacific tropical cyclone climatology and linkages to the El Niño-Southern Oscillation. J Clim 26:3-25

Donnelly JP, Woodruff JS (2007) Intense hurricane activity over the past 5000 years controlled by El Niño and the west African monsoon. Nature 447:465-468

Donnelly JP, Hawkes AD, Lane P, MacDonald D, Shuman BN, Toomey MR, van Hengstum PJ, Woodruff JD (2015) Climate forcing of unprecedented intense-hurricane activity in the last 2000 years. Earth's Future 3:49-65

Elsner JB, Kossin JP, Jagger TH (2008) The increasing intensity of the strongest tropical cyclones. Nature 455:92-95

Emanuel KA (2005) Increasing destructiveness of tropical cyclones over the past 30 years. Nature 436:686-688

Forsyth A, Nott J, Bateman M (2010) Beach ridge plain evidence of a variable late-Holocene tropical cyclone climate, north Queensland, Australia. Palaeogeogr Palaeoclimatol Palaeoecol 297:707-716

Frappier A, Knutson T, Liu K (2007) Perspective: coordinating paleoclimate research on tropical cyclones with hurricane-climate theory and modelling. Tellus 59A:529-537

Haig J, Nott J, Reichart G-J (2014) Australian tropical cyclone activity lower than at any time over the past 550-1500 years. Nature 505:667-670

Haigh ID, Wijeratne EMS, MacPherson LR, Pattiaratchi CB, Mason MS, Crompton RP, George S (2014) Estimating present day extreme water level exceedance probabilities around the coastline of Australia: tropical cycloneinduced storm surges. Clim Dyn 42:139-157

Hall T, Jewson S (2008) Comparison of local and basin wide methods for risk assessment of tropical cyclone landfall. J Appl Meteorol Climatol 47:361-368

Hallegatte S, Ranger N, Mestre O, Dumas P, Corfee-Morlot J, Herweijer C, Muir Wood R (2011) Assessing climate change impacts, sea level rise and storm surge risk in port cities: a case study on Copenhagen. Clim Change 104:113-127

Hardy T, Mason L, Astorquia A (2004) Surge plus tide statistics for selected open coast locations along the Queensland east coast. Queensland climate change and community vulnerability to tropical cyclones. Ocean hazards assessment Stage 3. Queensland Government Report, July 2004

Hendy EJ et al (2002) Abrupt decrease in tropical Pacific sea surface salinity at end of little ice age. Science 295:1511-1514

Hesp PA (2006) Sand beach ridges: definitions and re-definition. J Coast Res 39:72-75
Holland G, Bruyere CL (2013) Recent intense hurricane response to global climate change. Clim Dyn 42:617-627

Kossin JP, Emanuel KA, Vecchi GA (2014) The poleward migration of the location of tropical cyclone maximum intensity. Nature 509:349-352

Lin N, Lane P, Emanuel K, Sullivan R, Donnelly J (2014) Heightened hurricane surge risk in Northwest Florida revealed from climatologicalhydrodynamic modeling and paleorecord reconstruction. J Geophys Res 119:1-18

Liu K, Fearn M (2000) Reconstruction of prehistoric landfall frequencies of catastrophic hurricanes in Northwestern Florida from lake sediment records. Quatern Res 54:238-245

Maragos J, Baines G, Beveridge P (1973) Tropical cyclone bebe creates a new land formation on Funafuti Atoll. Science 181:1161-1164

McInnes K, Walsh K, Hubbert G, Beer T (2003) Impact of sea level rise and storm surges on a coastal community. Nat Hazards 30:187-207

N Lin, K Emannuel (2015) Grey swan tropical cyclones. Nat Clim Change 6:106-112

Nott JF (2003) The intensity of prehistoric tropical cyclones. J Geophys Res, 108: No. D7, 4212-4223

Nott JF (2006) Extreme Events: a physical reconstruction and risk assessment. Cambridge University Press, Cambridge 300p

Nott J (2011) Tropical cyclones, global climate change and the role of quaternary studies. J Quat Sci 26:468-473

Nott JF (2015) A rapid, economical and accurate method to determining the physical risk of storm marine inundations using sedimentary evidence. Geophys Res Lett 42:2426-2433. doi:10.1002/2015GL063288

Nott J, Forsyth A (2012) Punctuated global tropical cyclone activity over the past 5000 years. Geophys Res Lett 39:L14703. doi:10.1029/2012GL052236

Nott J, Hayne M (2001) High frequency of 'super-cyclones'along the Great Barrier Reef over the past 5000 years. Nature 413:508-512

Nott J, Jagger T (2013) Deriving robust return periods for tropical cyclone inundations from sediments. Geophys Res Lett 40:370-373

Nott J, Haig J, Neil H, Gillieson D (2007) Greater frequency variability of land falling tropical cyclones at centennial compared to seasonal and decadal scales. Earth Planet Sci. Lett 255:367-372

Nott J, Smithers S, Walsh K (2009) Sand beach ridges record 6000 year history of extreme tropical cyclone activity in Northeastern Australia. Quatern Sci Rev 28:1511-1520

Sachs J et al (2009) Southward movement of the Pacific intertropical convergence zone AD 1400-1850. Nat Geosci 4:519-525

Webster PJ, Holland GJ, Curry JA, Chang HR (2005) Changes in tropical cyclone number, duration, and intensity in a warming environment. Science 309:1844-1846

Woodruff JD, Donnelly JP, Mohrig D, Geyer WR (2008) Reconstructing relative flooding intensities responsible for hurricane-induced deposits from Laguna Playa Grande, Vieques. Puerto Rico Geol 36(5):391-394

Woodruff JD, Kanamaru K, Kundu S, Cook TL (2015) Depositional evidence for the Kamikaze typhoons and links to changes in typhoon climatology. Geology 43(1):91-94

Yan $\mathrm{H}$ et al (2011) A record of the Southern oscillation Index for the past 2000 years from precipitation proxies. Nat Geosci 4:611-614

\section{Submit your manuscript to a SpringerOpen ${ }^{\circ}$ journal and benefit from:}

- Convenient online submission

- Rigorous peer review

- Immediate publication on acceptance

- Open access: articles freely available online

- High visibility within the field

- Retaining the copyright to your article

Submit your next manuscript at $>$ springeropen.com 